\title{
Reconfigurable Manufacturing: Lesson Learnt from the COVID-19 Outbreak
}

\author{
Alessia Napoleone $\mathrm{e}^{1[0000-0002-0622-5011]}$ and Lorenzo Bruno Prataviera ${ }^{2[0000-0001-8821-7498]}$ \\ ${ }^{1}$ Department of Materials and Production, Aalborg University, Aalborg, Denmark \\ ${ }^{2}$ Department of Management, Economics and Industrial Engineering, Politecnico di Milano, \\ Milano, Italy \\ alna@mp.aau.dk
}

\begin{abstract}
To compete in the current volatile and unpredictable context, manufacturing firms increasingly need reconfigurability, i.e. the capability to adapt the production capacities and functionalities of their manufacturing systems according to evolving product families. To be attractive for practitioners, reconfigurability should require a reasonably low effort. In 2020, the COVID-19 outbreak has quickly twisted market requirements: in an unexpected market context, many firms have been reconfiguring their plants and networks to satisfy, with low efforts, the surge in the demand for very specific products. This paper analyses the reaction upheld by specific Italian manufacturing firms to the outbreak, to derive practical insights on possible ways to achieve reconfigurability in manufacturing. As for results, four insights are provided, regarding: the pre-existing know how held by firms; their network configuration; the modularity of products; and the use of smart and digital technologies. Additionally, remarking the relevance of collaboration between different firms, this paper sows the seeds for linking the reconfigurability theory with the dynamic capabilities theory.
\end{abstract}

Keywords: Reconfigurable Manufacturing, Scalability, Convertibility, COVID-19.

\section{Introduction}

Manufacturing companies are nowadays dealing with volatile and unpredictable market requirements and, to keep their competitiveness over time, they need to develop the reconfigurability capability $[1,2]$. Reconfigurability - referred to as changeability at plant and firm levels in several papers - is the capability of a manufacturing firm to repeatedly change or rearrange its manufacturing systems with a reasonable effort in order to produce evolving product families [3, 4]. Indeed, reconfigurability allows to provide the exact production capacities and functionalities needed, when needed [5]. To make reconfigurability attractive for practitioners, reconfigurations should require reasonably low efforts, in terms of reconfiguration time, cost and ramp-up time [6, 7].

The year 2020 will be certainly remembered for the COVID-19 pandemic. This virus affects the respiratory system and, in the frequent event of complications of the infection, people need support of breathing and intensive care. The virus has spread rapidly from China to all over the world, putting health systems of many countries into a crisis: 
the rapid contagion of many people determines the overcrowding of hospitals. For this reason, many governments have been imposing partial or total lockdowns. As an added precaution, people have been required to wear masks when leaving their homes and to sanitize frequently their hands. In this landscape, a huge demand for masks and sanitizing gels from common people and ventilators from hospitals has been rising and has been replacing the demand for manufacturing items such as clothing and vehicles.

In this new and unexpected scenario, some firms have been reconfiguring their plants and networks to satisfy, in a very short time period and at affordable costs, the high request for masks, sanitizing gels and ventilators. Indeed, given the emergency situation, these firms have kept the reconfiguration effort as low as possible. For this reason, such crisis can add interesting insights on how to achieve reconfigurability in manufacturing. Thus, the research question addressed in this paper is: "What reconfigurabilityrelated insights are manufacturing firms reacting to the COVID-19 outbreak providing to the academic and business communities?” Specifically, this research captures concrete insights from the reactions - during the period from February to April 2020 - to the outbreak of a group of Italian manufacturing firms serving the Italian market. To this end, section 2 provides a theoretical frame to the research, section 3 describes the adopted methodology, section 4 carries out the analysis and outlines the results of the investigation and section 5 provides the conclusions and feedback for further research.

\section{Theoretical frame}

According to literature, the characteristics of reconfigurability are: modularity, integrability, diagnosability, scalability, convertibility and customization. Modularity and integrability mean the functionalities of the system and its components being separated into units with standard interfaces that can be easily combined and changed [8]. Modularity and integrability are closely related $[1,9]$. Diagnosability allows quick identification of the sources of quality and reliability problems [10] and quick correction of operational problems [11] within the manufacturing system. Scalability allows incremental changes of capacity, rapidly and economically [12]. Convertibility 'allows quick changeover between existing products and quick system adaptability for future products' [10]. Customization allows adaptation of system configuration for producing the required product families $[4,10]$. These characteristics are relevant as they allow reducing the reconfiguration effort, making reconfigurability attractive for practitioners.

Among the 6 characteristics, scalability and convertibility are those directly related to manufacturing systems' responsiveness to sudden changes: scalability to changes in demand and convertibility to changes in product mix [13]. Indeed, scalability and convertibility directly contribute to the goal of the reconfigurable systems, which is providing exactly the capacity and functionality needed when needed [5, 14].

Several authors have worked at the identification of enablers of scalability and convertibility (see for example [6, 14-16]. Specifically, this paper relies on the observation that, being "reconfiguration" characteristics (i.e. directly related to systems responsiveness to changes), scalability and convertibility are supported by "configuration” enablers such as the modularity and integrability characteristics $[17,18]$. 


\section{$3 \quad$ Research design}

This study examined implemented actions in terms of changes in the production capacity and/or functionality of production systems and identified the enablers of such actions; thus, providing insights on enablers of scalability and convertibility. Multiple cases were analyzed to increase external validity and to reduce risks to misjudge singular events [19]. As units of analysis, Italian manufacturing firms of different sizes, serving the Italian market and reacting to the COVID-19 outbreak from February to April 2020 were considered, as Italy emerged as one of the countries that was hardest hit by the epidemic. Given the dramatic situation, it was not possible to directly interview firms' representatives. Consequently, the main sources of information for the analysis were firms' websites and national business magazines. To corroborate the evidences and to strengthen a formal chain of evidence, a formal database was established [20]. To support study's construct validity, multiple data sources were triangulated, and additional materials available online, such as industry reports or public documents, were included in the database [19]. In addition, to increase study's internal validity the collected information was contextualized into the available theory on reconfigurability.

Sample selection was based on a theoretical sampling, driven by the opportunity to gain accessibility to the type of phenomenon of interests [20]. The sample of investigation is represented in the following table (Table 1). Overall, 21 cases were selected. Although this convenience sample may have determined a possible bias [20], this was considered coherent with the aim of this investigation, i.e. to observe general trends in the existing scenario and to provide prompt insights for further research.

Table 1. Sample of investigation

\begin{tabular}{|c|c|c|c|c|}
\hline Firm (id) & Sector & Size & Product & Production stages \\
\hline F.1.1 & rubber and plastics & L & ventilators & all stages \\
\hline F.1.2 & Weapons & L & ventilators & manufacturing of a component \\
\hline F.1.3 & manufacturing consultancy & S & ventilators & manufacturing of a component \\
\hline F.2.1 & textile and clothing (luxury) & L & masks & all stages \\
\hline F.2.2 & textile and clothing (luxury) & M & masks & all stages \\
\hline F.2.3 & textile and clothing (luxury) & L & masks and medical scrubs & all stages \\
\hline F.2.4 & textile and clothing & L & masks and medical scrubs & all stages \\
\hline F.2.5 & textile and clothing (luxury) & L & masks and medical scrubs & all stages \\
\hline F.2.6 & textile and clothing & S & masks & manufacturing of fabrics \\
\hline F.2.7 & textile & S & masks & all stages \\
\hline F.2.8 & textile & S & masks & all stages \\
\hline F.2.9 & textile and clothing & S & masks & all stages \\
\hline F.2.10 & textile & L & Masks & all stages \\
\hline F.2.11 & luxury packaging & S & Masks & all stages \\
\hline F.3.1 & pharmaceutical & L & sanitizing gel & all stages \\
\hline F.3.2 & chemicals (hair products) & L & sanitizing gel & all stages \\
\hline F.3.3 & chemicals (cosmetics) & M & sanitizing gel & some phases \\
\hline F.4 & medical devices & M & membrane oxygenator & some phases \\
\hline F.5.1 & medical devices & S & Ventilators & \\
\hline F.5.2 & Automotive & L & ventilators & \\
\hline F.5.3 & Automotive & L & Ventilators & \\
\hline
\end{tabular}

Table 1 provides general information about the cases, including the industry in which they operate. Firms' names are not provided for confidentiality reasons. In the last two columns, Table 1 specifies the outcome of the production process (i.e. the final product)

\footnotetext{
${ }^{1}$ According to the European Commission, classification in Large (L), Medium (M) and Small (S) firms (based on number of employees)
} 
and the production stage in which each firm contributed. Indeed, some firms were involved in all production stages, while some others contributed in specific stages of the manufacturing process of the final product. As shown in Table 1, cases were divided into 5 groups according to the presence of sectorial commonalities or due to the collaboration among firms with respect to the final product. This classification supported the interpretation of the results of the analysis as clarified in the following section.

\section{$4 \quad$ Analysis of the cases and results}

The great majority of the analyzed firms (except F.3.1, operating in the pharmaceutical industry, and F.4 and F.5.1, producing medical devices) would have had their plants closed down. This was due to both (i) the absence of demand for their products (e.g. the luxury clothing, the cosmetics and the cars) and (ii) the fact that the Italian Government ordered the temporary suspension of non-critical production.

\subsection{Analysis of the cases}

To support the analysis and the interpretation of results, the 21 cases have been sorted into five groups (see Table 1).

The first group includes two firms from different sectors, which both cooperated with F.1.3 - a consulting company operating in the field of the industrial and mechanical engineering - in order to provide ventilators to Italian hospitals. Specifically, F.1.3 patented a 3D printed valve to turn snorkeling masks into ventilators. Thanks to F.1.3's idea, low cost ventilators could be manufactured and made available in a very short time period. Consequently, F.1.1, manufacturer of snorkeling masks, started collaborating with F.1.3 and realized a mold that allowed the industrialization of the valve, thus furtherly increasing the production of ventilators. In addition, F.1.2, a producer of weapons, also cooperated with F.1.3 by using its 3D prototyping printers for the production of the valve. To quickly identify suppliers for the required raw materials, F.1.2's Chief Executive Officer exploited social media virtual networks. In this way, the firm found suppliers of raw materials from both Italy and Germany.

The second group includes 11 firms from the textile and clothing industry (except F.2.11, which produces customized luxury packaging). They all supplied masks to hospitals and pharmacies. F.2.1 quickly introduced a new treatment at one of its printing plants to make water-repellent fabric (involving around 50 people). Moreover, it involved its distribution partners all over the Italian territory (around 500 people) for the packaging and distribution of masks. Overall, it already had the required know-how and technology, but needed to widely increase the production capacity at the fabric printing plant. F.2.2 completely revolutionized its operations, with tailors working from home to produce and pack masks. Every day, staff people brought the non-woven fabrics, rubber bands and underwire to the tailors, while collecting ready-for-distribution masks. F.2.4 acquired special machines to realize a semi-automatic line to produce masks and medical scrubs, and exploited digital technologies to train tailors. F.2.8 and F.2.10 reconverted their production plants in record time to provide masks. Finally, 
F.2.11 exploited its operations and expertise to use the material normally used to pack jewelry items to produce masks.

The third group includes three firms operating in the chemicals industry, including the pharmaceutical and the cosmetics ones, which produced sanitizing gel. For example, F.3.1 dedicated one of its plants (already dedicated to the production of medication in gel) to the sole production of the sanitizing gel.

F.4 is the smallest (and the only Italian) firm in the world producing extracorporeal membrane oxygenators. These devices are used in hospitals for patients in extreme situations, where also ventilators are not enough to support the breathing activity of people. It quadrupled its production capacity in a few weeks by moving 130 people out of 220 total employees on the production systems.

The last group of firms includes F.5.1, a firm producing medical devices, and 2 firms within the automotive industry, which have been grouped due to their collaboration to produce ventilators. F.5.1 is the only Italian firm producing ventilators and experienced a sudden increase in the demand for such devices. Thus, it collaborated with F.5.2 and F.5.3, who manufactured some components and supported some assembly phases for the ventilators production.

As regards the automotive industry, it deserves further exploration: international firms operating out of Italy can add relevant insights to the results of the present investigation. Indeed, being characterized by high technology investments, the automotive industry can provide a variety of different product families, such as masks, protective visors, and even ventilators. In Brazil, a firm used 3D printing to produce masks; in Spain, another firm used 3D printers to manufacture visors; in Germany, two others used 3D printers to manufacture ventilators; finally, two further firms in China assembled protective suits and masks.

\subsection{Results of the investigation}

Overall, the results of this analysis in terms of reconfigurability can be synthesized in four main points, which have been also represented in Figure 1:

1. Current know how held by firms. As stated in Section 2, reconfigurability should allow a firm to change or rearrange its manufacturing systems so to be able to produce any kind of product family. The epidemic has shown that to ensure reasonable efforts, firms rearranging their operations should be already provided with the required know how. For example, firms in the textile and clothing industry supplied masks, while firms in the chemical sector supplied sanitizing gel. Conversely, the automotive appears as the most reconfigurable industry, as these firms were capable to provide a variety of different product families thanks to the exploitation of up to date technologies.

2. Configuration of the network of firms involved in the value chain of the end products. The many examples of successful collaboration not only confirmed the importance of inter-firm linkages to create value, but also demonstrated that capabilities can be synergistically combined or exploited by supply chain partners [21].

3. Modularity of products. According to literature, it enables the modularity and integrability characteristics of manufacturing processes [22-24]. To this end, the modularity of the product given by the combination of the snorkeling mask with the recently 
patented valve is very representative. On the one hand, it allowed F.1.1 to clearly identify the specific processes needing reconfiguration, i.e. manufacturing a mold to produce the new valve instead of the traditional valve needed by conventional snorkeling masks. Moreover, regarding F.1.2, the modularity of the end product allowed the firm to clearly identify its role in the overall value chain, i.e. converting its prototyping department to produce the valves and supply them to F.1.1.

4. Smart and digital technologies. The possibility to remotely train employees (in this specific situation, to avoid the spread of the virus) is an interesting enabler of reconfigurability. Combined with augmented reality technologies, remote training is a powerful tool to support the "conversion” of operators' skills within plants. Also, the use of social media to share information and potentially build new network collaborations (as per F1.2) provides some food for thoughts. Finally, 3D printing is a very powerful technology to achieve conversion of specific functionalities, as brightly shown in the many examples in the automotive industry.

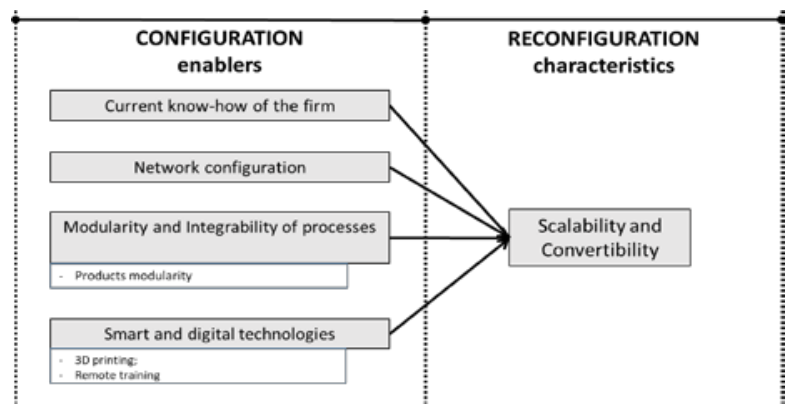

Fig. 1. A representation of the results of the investigation (adaptation of part of the framework provided by [17])

Lastly, collaboration between firms along products' value chains supported the reduction of the reconfiguration effort, as it allowed to distribute roles along the value chain based on the available plants and know-how of each entity. For this reason, further research could broaden the perspective from a firm-level to a supply chain-level, by exploring the link between the reconfigurability theory and other well-established theories, e.g. the dynamic capabilities theory. Dynamic capabilities are defined as the firm's abilities “to integrate, build, and reconfigure internal and external competences to address rapidly changing environments" [25], and have been progressively expanded from a resource-based view approach (i.e. how firms create competitive advantage and value) to address the relationships a firm has with other firms, as managing inter-organizational relationships is a key to success [26]. Some researchers argued that the dynamic capabilities theory helps address how to respond to the business changing environment, but may fail to describe exactly the capabilities to be operationalized [26]. By linking the dynamic capabilities theory with the reconfigurability theory, it might be possible to bridge the organization's capacity to efficiently and responsively change operations and develop its resources [25], with the actions and efforts required at different manufacturing levels, from the workstation to the plant $[4,17]$. 


\section{Conclusions}

In order to face the COVID-19 outbreak, many firms have been reconfiguring their plants and networks to satisfy, with low reconfiguration efforts, the surge in the demand for specific products such as masks, sanitizing gels and ventilators. Based on the analysis of reactions of selected manufacturing firms to this crisis, this paper provides some practical insights on enablers of the scalability and convertibility characteristics, thus on possible ways to achieve reconfigurability in manufacturing.

The main limitation of this work is that, given the dramatic situation, it was not possible to conduct in-depth analysis of the cases. Indeed, in future research, the authors aim at focusing on a limited number of the cases analyzed in this paper in order to enrich the insights collected in this paper. On the other hand, focusing on multiple cases, this investigation aimed at providing prompt and as broad as possible food for thought for both academics and practitioners. Indeed, the analysis has brought into light two aspects offering high potentialities to the reconfigurability theory and thus deserving further research. These are: (i) smart and digital technologies, which support the characteristics of scalability and convertibility and (ii) collaboration along value chains, which promises to reduce reconfiguration efforts. Regarding the latter, this paper sows the seeds for linking the reconfigurability theory with the dynamic capabilities theory.

\section{References}

1. Shaik AM, Rao VVSK, Rao CS (2015) Development of modular manufacturing systems a review. International Journal of Advanced Manufacturing Technology 76:789-802

2. Setchi RM, Lagos N (2004) Reconfigurability and Reconfigurable Manufacturing Systems - State-of-the-art Review. In: 2nd IEEE International Conference on Industrial Informatics. pp 529-535

3. Azab A, ElMaraghy HA (2007) Mathematical Modeling for Reconfigurable Process Planning. CIRP Annals - Manufacturing Technology 56:467-472.

4. Rösiö C (2012) Supporting the design of reconfigurable production systems

5. Koren Y (2006) General RMS Characteristics. Comparison with Dedicated and Flexible Systems. In: Chapter 3 in Reconfigurable Manufacturing Systems and Transformable Factories. pp 27-45

6. Andersen A-L, Larsen JK, Brunoe TD, Nielsen K, Ketelsen C (2018) Critical enablers of changeable and reconfigurable manufacturing and their industrial implementation. Journal of Manufacturing Technology Management 29:983-1002.

7. Goyal KK, Jain PKK, Jain M (2012) Optimal configuration selection for reconfigurable manufacturing system using NSGA II and TOPSIS. International Journal of Production Research 50:4175-4191.

8. Andersen A-L, Brunoe TD, Christensen B, Bejlegaard M (2019) Tailored Reconfigurability: A Comparative Study of Eight Industrial Cases with Reconfigurability as a Key to Manufacturing Competitiveness. In: Reconfigurable Manufacturing Systems: From Design to Implementation. pp 209-245

9. Mehrabi MG, Ulsoy AG, Koren Y, Heytler P (2002) Trends and perspectives in flexible and reconfigurable manufacturing systems. Journal of Intelligent Manufacturing 13:135-146. 
10. Mehrabi MG, Ulsoy AG, Koren Y (2000) Reconfigurable manufacturing systems and their enabling technologies. International Journal of Manufacturing Technology and Management $1: 1-21$

11. Gumasta K, Kumar Gupta S, Benyoucef L, Tiwari MK (2011) Developing a reconfigurability index using multi-attribute utility theory. International Journal of Production Research 49:1669-1683.

12. Elmaraghy HA (2006) Flexible and reconfigurable manufacturing systems paradigms. International Journal of Flexible Manufacturing Systems 17:261-276.

13. Maganha I, Silva C, Ferreira LMDF (2018) Understanding reconfigurability of manufacturing systems: An empirical analysis. Journal of Manufacturing Systems 48:120-130.

14. Napoleone A, Andersen A-L, Pozzetti A, Macchi M (2019) Reconfigurable Manufacturing: A Classification of Elements Enabling Convertibility and Scalability. In: IFAC PapersOnLine. pp 349-356

15. Beauville A, Klement N, Gibaru O, Roucoules L, Durville L (2019) Identification of reconfigurability enablers and weighting of reconfigurability characteristics based on a case study. In: Procedia Manufacturing. pp 96-101

16. Rösiö C, Aslam T, Banavara K, Shetty S (2019) Towards an assessment criterion of reconfigurable manufacturing systems within the automotive industry. In: Procedia Manufacturing. pp 76-82

17. Napoleone A, Pozzetti A, Macchi M (2018) A framework to manage reconfigurability in manufacturing. International Journal of Production Research 56:3815-3837.

18. Singh A, Gupta S, Asjad M, Gupta P (2017) Reconfigurable manufacturing systems : journey and the road ahead. International Journal of System Assurance Engineering and Management 8:1849-1857.

19. Voss C, Tsikriktsis N, Frohlich M (2002) Case research in operations management. International Journal of Operations \& Production Management 22:195-219.

20. Yin RK (2009) Case Study Research, 4th edition.

21. Zacharia ZG, Sanders NR, Nix NW (2011) The emerging role of the third-party logistics provider (3PL) as an orchestrator. Journal of Business Logistics 32:40-54.

22. Brunoe TD, Andersen AL, Sorensen DGH, Nielsen K, Bejlegaard M (2019) Integrated product-process modelling for platform-based co-development. International Journal of Production Research 0:1-17.

23. Sorensen DGH, Elmaraghy H, Ditlev T, Nielsen K (2020) Classification coding of production systems for identification of platform candidates. CIRP Journal of Manufacturing Science and Technology 28:144-156

24. Joergensen SN, Hvilshøj M, Madsen O (2012) Designing modular manufacturing systems using mass customisation theories and methods. International Journal of Mass Customisation $4: 171$.

25. Teece DJ, Pisano G, Shuen AMY (1997) Dynamic Capabilities and Strategic Management Authors. Strategic Management Journal 18:509-533

26. Wang, Catherine L; Ahmed P. (1895) Dynamic Capabilities: A Review and Research Agenda. The International Journal of Management reviews 9:31-51. 